\title{
Organisational and Strategic COMMUNICATION: EDITORIAL INTRODUCTION
}

\author{
Teresa Ruão \& Margarida Kunsch \\ CECS - University of Minho, Portugal / University of São Paulo, Brazil
}

The study of communication in organisations - in a broad sense, and without source scientific field restrictions (which included traditional research into Organisational Communication, Public Relations, Institutional Communication, Internal Communication, Advertising, Promotion or Corporate Communication, among others) - seeks to offer an understanding of the processes, scenarios and challenges of communicating and organising in the context of a global society. It is therefore a broad area with multiple perspectives. And communication researchers have dedicated themselves to developing concepts and theories that assist a better understanding of this social environment, as research tools and instruments to support organisational practices.

The perspective of this phenomenon from the field of Communication studies is, however, very peculiar and rich. Their strongest differentiator is maybe owed to Karl Weick, who argued that organising is essentially a communication phenomenon, by stating that «the communication activity is the organization» (Weick, 1995: 75). Weick (1979) recalled that human beings continuously reconstruct reality through meaning attribution mechanisms that rationalise the sense of their actions. Building upon this principle, the author argued that communication is core to human life and, in particular, to organisations, because it is the core process of organising. Communication would thus be organisation. Weick thus challenged the communication metaphor as container of information flows (a classic idea of Organisational Communication studies), suggesting that research in the field should focus on the transversal role apparently played by communication in creating organisational systems with a single social order.

This proposal eventually resulted in a theoretical and research trend in Organisational Communication based on the key idea of the communicative nature of organisations, which was encapsulated in the famous declaration about the 'communicative constitution of organisations' and the corresponding abbreviation, 'CCO'. Researchers into Organisational Communication have since appeared to be increasingly interested in extending and resizing the $\mathrm{CCO}$ perspective, whose theoretical framework has been developed by three different schools of thought: the Montreal School of Organizational Communication (Cooren, Taylor or Van Every), the Four-Flows Model (McPhee and Zaug, among others; based on Giddens's structuration Theory), and Luhmann's Theory of Social Systems (Schoeneborn et al., 2014). Notwithstanding their diverging opinions, those who proposed this perspective agree that organisations are created and developed by the communication practices - an idea support by the assumption that reality is a socially constructed phenomenon. They therefore bring Communication studies closer to Organisational studies, resorting to a holistic, integrated and enriching perspective. 
Hence, CCO has been asserting itself as the benchmark theoretical framework in the field, structuring the epistemological, ontological and methodological dimensions of research into communication in organisations. Moreover, it is assumed that, in all these dimensions, organisations exist through communication and build themselves through the interaction relationships that take place inside, as well as in their relationship with the outside.

In this regard, we recall also another differentiating idea of organisations, from the perspective of Communication Sciences: the assumption that organisational relationships are far from taking place in ordered and rational environments. As Weick stated, organisations are stable and rational structures only when viewed retrospectively. And current organisational environments are so turbulent and globalised that instrumental, rational or efficient communication becomes an unattainable myth. To that extent, the view of Organisational Communication has evolved to frame as well the winds of change of organisations, in the workplace, in markets, and in society at large, operated in recent years.

This understanding lies, in fact, at the centre of Organisational Communication research, which has been developing its very own map of reality. Researchers in the field consider that organisations are complex social communities, which can be investigated and explained by means of a communicative framework; since communication is part of the organisation process, it is its very substance that fuels this process, as their practices give rise to complex and diverse systems of meaning. Thus, their research has challenged the economic concepts prevailing in the social and business world, drawing attention to alternative structures, political issues, gender matters, cultural practices or peculiarities of collective behaviour. And this concern about the organisation itself is that which distinguishes, essentially, the Organisational Communication from marketing, management or business proposals.

'...an organisation is a communication system that allows large communities of human beings to interact and work, having a sufficiently shared understanding that they can deploy their business by setting up, at least apparently, a coherent community of interests' (Taylor, 1993: 104).

Organisations are therefore understood by Organisational Communication theorists as groups of people working collectively towards a common goal, by developing specialised activities. It is the crucial task of communication to coordinate the overall organisation's capabilities. Hence, James Taylor's statement that communication is the 'glue of the organisation', as it enables achieving coordination with a minimum effort and a minimal cost control. This accounts for the understanding that a productive organisation is an entity with a 'good' communication system, whereas an unproductive organisation appears to stem from a 'poor' communication system.

Building upon this proposal for interpreting reality, which was deployed by Organisational Communication, other trends have asserted themselves in the meantime, in the context of communication studies in companies and institutions. We refer to Strategic Communication, an approach that emerges from the competitive environment that 
surrounds current organisations. In fact, contemporary organisations seem compelled to deal with a multitude of different publics, fragmented audiences and contact platforms that cross the traditional boundaries of the marketing work (focused on the product or brand). Therefore, communication departments have taken on the role of global communication planners of the organisation, including the institutional and commercial dimensions. In this context, they deploy holistic, controlled and hyper-imagined communication strategies, in which the campaign intention is minutely planned and programmed. Moreover, this framework is a new challenge to Communication Sciences studies.

The field has responded to this challenge by resorting to the growing interest for the analysis of the strategic dimension of communication in organisations. As a result, a new approach to Organisational Communication, called Strategic Communication, has asserted itself, which studies the intentional use of communication by an organisation in order to achieve its objectives (Hallahan et al., 2007). Or, in the words of Argenti et al. 2005: 83), an area that analyses 'communication aligned to the overall corporate strategy in order to achieve its strategic positioning.'

Taking into account the importance taken by this perspective in the academic field of Communication Sciences, in the research developed in postgraduate courses and in the market practices of Public Relations, Corporate and Government Communication, we decided that we should introduce the approach in this publication. In fact, its scientific studies have advanced a lot (with distinctive paths in different countries, obviously), especially in the last two decades, and we think that this will become a strong trend of this field in the coming years

Along with this reading of the future direction of Organisational Communication studies - which are hereby highlighted because they reflect the research area of the present volume -, we must recall that the scientific range dedicated to the understanding of communication in organisations is much wider. It also includes research into corporate communication, marketing, management or business, whose contribution to the understanding of the organizational reality is undeniably important.

This wide understanding was, moreover, at the basis of our initiative to dedicate a special issue of the Communication and Society journal, of the Communication and Society Research Centre of the University of Minho, to the topic Strategic and Organisational Communication, with the aim of providing an up-to-date perspective of the reflections and discussions in the scope of communication in the organisational environment. It is, therefore, intended to promote the dissemination of scientific production into these topics, the field of Communication Sciences, as in other, adjacent fields. Like Corman and Poole (2000), we believe that disciplinary disagreements can be extremely useful in constructing any scientific field, but when excessive they can also raise boundaries to quality work. Our proposal therefore consists of introducing a multidisciplinary issue that is open to any field of scientific studies that is interested in communication phenomena taking place in companies and institutions.

The result of this initiative is presented in the following pages of this issue. It begins with a first part entitled New Trends, Permanent Challenges, which includes a set of 
texts written especially for this journal by three renowned researchers in the field. Their presentation is organised following the line of thought described earlier. The first article reflects a scientific positioning based on Organisational Communication theories; the second discusses the Strategic Communication approach, and the third gives way to a more specialised research.

Thus João Figueira, from the University of Coimbra (Portugal), wrote the article A Vida é Bela: Institutionalisation Processes and Construction of Meaning through the Media, which discusses the process of institutionalisation of contemporary organisations through the media. This reflection builds upon an analysis of the case of the Portuguese company A Vida é Bela, which was the topic of 4,558 pieces published in the Portuguese media between 2005 and 2012. The results of this study show how an organisation can publicly assert their name by resorting to the deployment of a meaning construction strategy whose main public is the media. The author concludes that, currently, communication through the media is the main institutional form of action, which requires organisations to master the media routines and culture.

Victoria Carrillo, from the University of Extremadura (Spain), writes about Strategic Communication in the Communications Environment of Today's Organizations. In this paper, the author seeks to clarify the concept of Strategic Communication, while recognising its growing relevance as a scientific and professional field. To this end, she cites different authors that have contributed a definition and proposed theories in the field. It concludes that the role of communication should be part of the senior management capacities, and moreover that it should be aligned to the long-term objectives of the company and their stakeholders.

Gisela Gonçalves, from the University of Beira Interior (Portugal), presents the article Political Public Relations: Grassroots, Challenges and Applications. This article discusses Public Relations applied to the political arena as an emerging research site (when compared to Corporate Public Relations), albeit one with a great development potential. For that purpose, the author reflected on the subject by studying its conceptual grassroots and the challenges imposed on its practice by the new media. This article, which is theoretically framed by the theory of relationship management and by the ideal of symmetrical and dialogic communication, presents possible paths for applied research in the field of Political Public Relations.

The second part of this issue includes Impressions on Applied Communication, which shares the line of thought with the six articles selected for publication during the blind-reviewing process. They all represent an effort to bring the discipline closer to specialised fields of organisational communication, and they all present results of the applied scientific analysis.

Maria Eugênia Porém, Aline Mariano Macedo and Roseane Andrelo, from the State University of São Paulo, Universidade Estadual Paulista (Brazil), are the authors of the first article, entitled Organizational Communication and Innovation in Micro and Small Businesses: A Study on the application of the 'Innovation Radar'. This study investigates the role of communication in the innovation process of small businesses. To this end, 
the researchers developed a diagnostic tool, which they called 'Innovation Radar', based on empirical research applied to a company in the State of São Paulo. The diagnosis, which assesses the maturity and the degree of innovativeness in micro and small businesses, highlighted the influence of organisational communication on promoting this innovativeness.

Marcio Simeone Henriques and Daniel Reis Silva, from the Federal University of Minas Gerais (Brazil), analysed the Public's vulnerability against abusive practices of communication employed by organizations: limitations for civil monitoring. In this work, they reflect on the relevance of the civil monitoring of abusive communication practices employed by private organisations. The authors suggest that these practices, which influence the public opinion, create communication categories often diffuse and whose recognition is difficult. The work specifically explores the practice of astroturfing, which is described as a manifestation of a simulated public, to reflect on their ethical boundaries.

Danusa Santana Andrade, from the Federal University of Mato Grosso do Sul (Brazil), authored the article The Governmental Communication of President Dilma Rousseff: A Content Analysis of the Presidency of the Republic Portal. This study thus presents a content analysis of governmental communication strategies of the Presidency of the Republic of Brazil, outlining a profile of Dilma Rousseff's administration. Their findings suggest that the administration of President Dilma through the online portal privileged the use of governmental communication strategies to the detriment of political marketing guidelines. This research discusses the public modes of communication of institutions with the society.

Éllida Neiva Guedes, Marcelo da Silva and Protásio Cézar dos Santos, from the Federal University of Maranhão (Brazil), discuss the Communicational efforts for the construction of relationships in contemporary society: mediations and technology. The authors discuss the need to align communication efforts to building lasting relationships between an organisation and their publics, in face of the ephemeral contemporary society. The approach to this topic resorts to Public Relations theories, which they use to highlight the relevance of integrating the various skills of communication professionals, considering the social and technological environment in which we live. They furthermore suggest that this integration enables the construction of sustained and lasting relational processes as primary needs of contemporary organisations.

Kathy Matilla, Guillem Marca-Francés and Andréa Oliveira, from the Ramon Llull, Vic and Girona Universities (Spain), respectively, wrote about the Audit Typologies used by Communication and Public Relations Directors and Agencies: a comparative analysis, Spain - ECM. This article presents a comparative study, conducted in Spain, to investigate the audit models used by communication directors of the largest companies in the country and by public relations agencies (partners of Dircom), compared to the methodologies used by their peers in other European countries (using European Communication Monitor data). The results highlight the trend towards an instrumental (tactical) orientation of the Spanish professional practice, as can be seen by the major use of audits clearly associated with results control. 
Helena Pires, from the University of Minho (Portugal), is the author of the article The Urban Landscape and Fashion Advertising: the Case of the DKNY Brand, which studies the investment of the fashion design industry in strategic communication as promoters of brand value. Her analysis begins with the study of how the urban landscape is constructed in fashion advertising, by identifying the main landscape referents represented, and seeking their association with the various cultural and artistic universes (such as literature, photography or cinema). It discusses outdoor advertising resorting to the case of the fashion brand Donna Karan New York - DKNY, which is considered to be paradigmatic of the research topic.

In Various section, Moisés de Lemos Martins, from the University of Minho (Portugal) has a text "in memory of José Augusto Mourão" (1948-2011), professor at the Universidade Nova de Lisboa. In the article, named In the fragile glow of existence, the seduction of the visible and the passion for the invisible, we get to know the personal, intellectual and academic trajectory of this semiotician, theologian, poet, musician, literary critic and Portuguese essayist.

This issue concludes with a critical review of the work Corporate Communication: A Guide to Theory and Practice, by Joep Cornelissen (2014 - 4th edition), authored by Celma Padamo, from the Instituto Superior de Novas Profissões (Portugal). This book explores the perspective of the field of Corporate Communication (strongly influenced by the theories of Management and Economics, and borrowing the term 'corporation' from the American tradition to mean an organisation in the form of company) to analyse the corporate communication activity and research conducted in the academia. This fourth edition, which revisits the classical subjects of this research tradition (such as identity, reputation or strategy) and updates its case studies, builds upon the assumption of the relationship between communication and the impact of globalisation on organisations. To that extent, it includes a new chapter on social media, organisational citizenship, transnational governance and emerging standards in the field of corporate social responsibility. The topics of the relationships between organisational communication and the media, internal communication and leadership are also advanced in comparison to earlier editions. Furthermore, the issues discussed are presented as positive contributions to the body of research into organisational and strategic communication, for its multidisciplinary nature and even for their emotional dimension, which is inseparable from the human phenomena.

\section{REFERENCES}

Argenti, P., Howells, R.A. \& Beck, K.A. (2005) 'The Strategic Communication Imperative', MIT Sloan Management Review, 46 (3): $83-89$.

Corman, S.R. \& Poole, M.S. (2000) Perspectives on Organizational Communication, Texas: Guilford Publications.

Hallahan, K., Holtzhausen, D., van Ruler, B., Ver i, D. \& Sriramesh, K. (2007) 'Defining Strategic Communication', International Journal of Strategic Communication, 1(1): 3-35. 
Popper, K. R. (1965) Conjectures and refutations: The growth of scientific knowledge, New York: Basic Books.

Schoeneborn, D., Blaschlke, S., Cooren, F., McPhee, R.D., Seidl, D. \& Taylor, J. (2014) 'The Three Schools of CCO Thinking: Interactive Dialogue and systematic comparison', Management Communication Quarterly, 28: 285-316.

Taylor, J. (1993) Rethinking the theory of organizational communication: how to read an organization, Norwood, $\mathrm{NJ}$ : Ablex

Weick, Karl (1979) The Social Psychology of Organizing, London: Random House.

Weick, Karl (1995) Sensemaking in Organizations, Thousand Oaks: Sage. 